\title{
Spatial regulation of proneural gene activity: auto- and cross-activation of achaete is antagonized by extramacrochaetae
}

\author{
Mark Van Doren, Patricia A. Powell, Dahna Pasternak, Andrew Singson, and James W. Posakony \\ Department of Biology and Center for Molecular Genetics, University of California San Diego, La Jolla, California \\ 92093-0322 USA
}

\begin{abstract}
The spatially restricted activities of achaete (ac) and scute (sc) are thought to define proneural clusters of potential sensory organ precursor cells in the imaginal discs of Drosophila. These genes encode transcriptional regulators of the basic helix-loop-helix (bHLH) class. We have found that direct, positive transcriptional autoregulation by the ac protein and cross-regulation by sc are essential for high-level expression of the ac promoter in the proneural cluster pattern and that autoactivation is important for the bristle-promoting function of the $a c$ gene. These auto- and cross-regulatory activities are antagonized in a dose-dependent manner by the inhibitory HLH protein encoded by the extramacrochaetae (emc) gene. We have found that $e m c$ is expressed in the wing imaginal disc in a pattern strongly complementary to that of the proneural clusters. Our results indicate that emc plays an essential early role in defining territories of bristle-forming potential.
\end{abstract}

[Key Words: Drosophila; neurogenesis; sensory organ development; transcriptional autoregulation; helix-loop-helix proteins; protein-protein interaction; pattern formation]

Received August 26, 1992; revised version accepted October 9, 1992.

The various types of sensory organs, or sensilla, that constitute the adult peripheral nervous system (PNS) of Drosophila are distributed on the body surface in a largely invariant pattern, the control of which offers a complex problem in the mechanisms of postembryonic pattern formation. Adult sensory organs develop during the late larval and early pupal stages within the imaginal discs and histoblast nests, epithelial sheets that give rise to the cuticular structures of the fly. Each sensillum is a multicellular sensory unit. For example, the mechanosensory bristles, typified by the macrochaetes and microchaetes of the head and thorax, are composed of a single bipolar neuron and three non-neuronal accessory cells. These four cells are the progeny, via a fixed lineage, of a single sensory organ precursor (SOP) cell (Hartenstein and Posakony 1989).

Genetic and molecular studies have identified two principal steps in the development of most adult sensory organs. In the first step, the localized activity of two genes, achaete $(a c)$ and scute $(s c)$, appears to confer on "proneural clusters" of cells in the imaginal disc the potential to become SOPs (Cubas et al. 1991; Skeath and Carroll 1991). Then, inhibitory cell-cell interactions mediated by the neurogenic class of genes restrict the expression of the SOP cell fate in each proneural cluster to a single cell. This cell comes to accumulate the highest amount of ac and sc protein and soon divides to give rise to an individual sensory organ; the remaining members of the proneural cluster become epidermal cells (Dietrich and Campos-Ortega 1984; Hartenstein and Posakony 1990; Simpson 1990; Cubas et al. 1991; Skeath and Carroll 1991). Thus, the mechanisms responsible for the spatially restricted activity of $a c$ and $s c$ in proneural clusters in the imaginal disc play an essential role in establishing the spatial pattern of sensory organs in the adult fly.

Both the $a c$ and $s c$ genes encode proteins of the basic helix-loop-helix (bHLH) class (Villares and Cabrera 1987; Alonso and Cabrera 1988; Murre et al. 1989) that are capable of sequence-specific DNA binding in vitro (Cabrera and Alonso 1991; Van Doren et al. 1991). The SOP cell fate also requires the activity of another, ubiquitously expressed bHLH protein that is the product of the daughterless (da) gene (Caudy et al. 1988a,b; Cronmiller et al. 1988; Cline 1989; Ghysen and O'Kane 1989|. In vitro, the intact ac and sc proteins exhibit DNA-binding activity only when they are part of hetero-oligomeric complexes with da (Cabrera and Alonso 1991; Van Doren et al. 1991). The sensillum-promoting activities of the $a c, s c$, and $d a$ genes are antagonized by the negative reg. ulators extramacrochaetae $(e m c)$ and hairy $(h)$. In emc and $h$ mutants, the ac and sc proteins are expressed ectopically in the wing imaginal disc /Cubas et al. 1991; Skeath and Carroll 1991), and sensory organs appear at ectopic sites in the adult (Moscoso del Prado and GarcíaBellido 1984; Lindsley and Zimm 1992). The emc and $h$ genes also encode HLH proteins (Rushlow et al. 1989; 
Ellis et al. 1990; Garrell and Modolell 199|. In particular, the emc protein contains the HLH dimerization domain characteristic of the HLH family but lacks the conserved basic region that constitutes the DNA-binding domain of the bHLH proteins, suggesting that its activity as a negative regulator is likely to depend on protein-protein, and not protein-DNA, interactions (Ellis et al. 1990; Garrell and Modolell 1990).

Recent evidence suggests that the $a c$ and $s c$ promoters are initially activated in the wing imaginal disc at distinct sites and that cross-activation between the two genes causes them to be expressed in the same final pattern (Martínez and Modolell 1991; Skeath and Carroll 1991). In addition, it has been shown that expression of the $a c$ and $s c$ promoters in the proneural clusters requires the activity of the respective endogenous genes (Martínez and Modolell 1991). That the ac and sc proteins could act directly as transcriptional regulators of the $a c$ gene was strongly suggested by the finding that the $a c$ promoter contains three E-box (CANNTG) sites that are bound specifically in vitro by $\mathrm{da} / \mathrm{ac}$ and $\mathrm{da} / \mathrm{sc}$ hetero-oligomeric protein complexes (Van Doren et al. 1991). It was demonstrated further that the emc protein is capable of specifically antagonizing this DNA-binding activity in a dose-dependent manner, suggesting that it acts at least in part as an inhibitor of $a c$ and $s c$ auto- and cross-regulation (Van Doren et al. 1991).

In this study we have investigated the specific functions of the ac, sc, and emc proteins that underlie their control of adult sensory organ patterning. We have found that ac and sc, when combined with da, can directly activate the $a c$ promoter. This direct transcriptional auto- and cross-regulation is essential for the correct expression of $a c$ in proneural clusters and for its bristlepromoting function. We have also found that the expression pattern of emc in the wing imaginal disc is largely complementary to that of $a c$ and that emc can interfere with ac- and sc-dependent activation of the ac promoter. We conclude that the emc protein plays an important early role in bristle patterning in part by post-translationally inhibiting the auto- and cross-regulatory activities of ac and sc in specific regions of the wing imaginal disc.

\section{Results}

\section{Transcriptional activation of the ac promoter}

We tested the ability of the $\mathrm{da}, \mathrm{ac}$, and sc proteins to activate transcription of the $a c$ promoter in a cotransfection assay in Drosophila tissue culture cells. The reporter gene consisted of a $0.9-\mathrm{kb}$ ac promoter fragment (Fig. 1A), containing the three previously identified da/ ac-sc DNA-binding sites (T5E1-T5E3; Van Doren et al. 1991), fused to the coding sequence of the bacterial chloramphenicol acetyltransferase (CAT) gene. The level of expression of this construct was measured either alone or in the presence of expression vectors containing da,

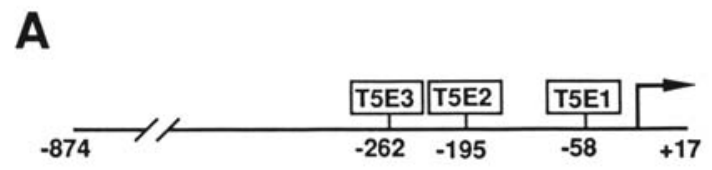

B

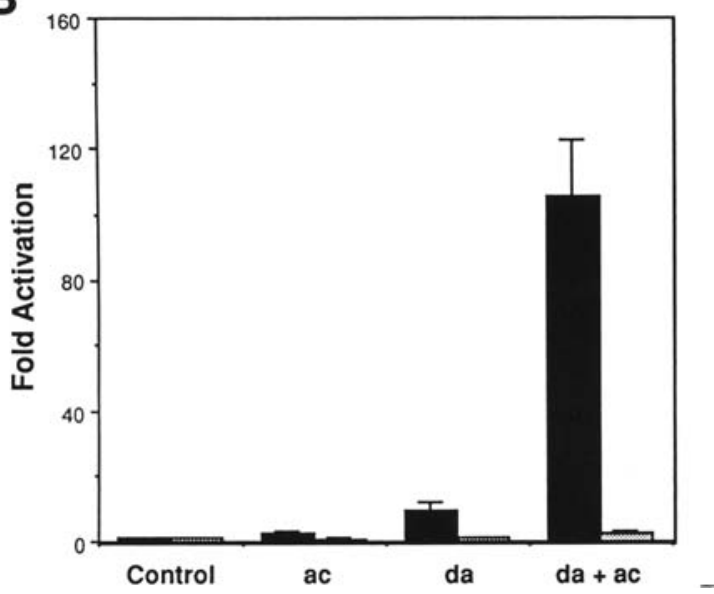

C

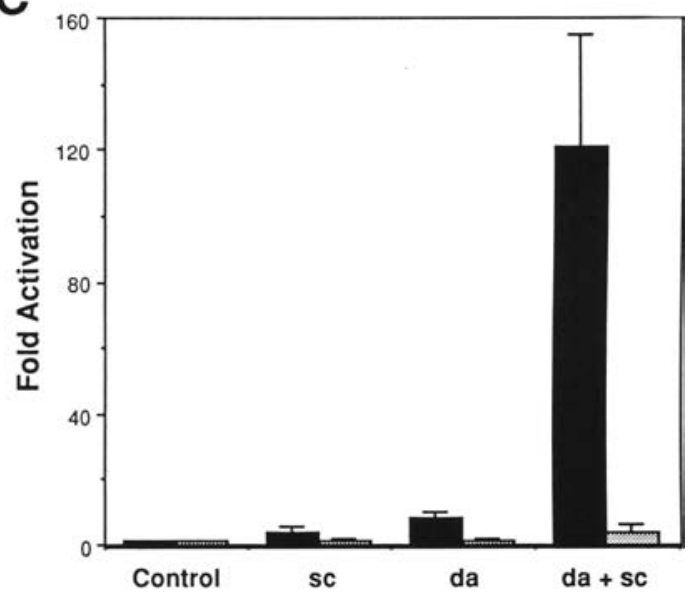

Figure 1. ac and sc, in combination with da, are potent activators of the $a c$ promoter. $(A)$ Diagram showing the upstream region of the $a c$ gene used to construct a promoter-CAT reporter gene. Previously identified E-box binding sites for da/ac-sc protein complexes (T5E1-T5E3) are indicated (Van Doren et al. 1991). In the mutant reporter construct, the E box (CANNTG) sequence at all three sites was mutated (to AANNTT). $(B, C)$ Pooled data from five $(B)$ and at least four $(C)$ independent tissue culture cotransfection experiments testing the ability of the ac, sc, and da expression vectors, individually and in combination, to elevate the expression of the $a c-C A T$ reporter gene over the level given by the reporter alone (control). Solid bars represent data for the wild-type ac promoter; shaded bars show data for the mutant promoter. Standard errors are indicated. 
ac, or sc protein-coding sequences under the control of the constitutive actin $5 \mathrm{C}$ promoter. The results are shown in Figure 1, B and C. Very little activation of the ac-CAT reporter gene above basal levels (two- to fourfold) is observed when the cells are cotransfected with the ac or sc expression vectors. Cotransfection of a da expression vector reproducibly gives an 8- to 10 -fold activation of $a c$ promoter expression. However, the highest levels of reporter gene activation, $>100$-fold, are observed when a combination of the ac and da, or the sc and $\mathrm{da}$, expression vectors are present in the transfection mixture. In contrast, a second ac-CAT reporter construct, identical to the first except for the introduction of two base pair mutations in each of the three da/ac-sc binding sites, fails to show significant activation under any of these conditions (Fig. 1B,C). This result strongly suggests that the ac and sc proteins act directly through the E-box binding sites to regulate the ac promoter.

The relative activities of the $\mathrm{da}$, ac, and sc proteins, individually and in combination, as activators of $a c$ transcription (Fig. 1) closely parallel their relative in vitro DNA-binding activities on the T5E1-T5E3 sites (Van Doren et al. 1991). The ac and sc proteins alone fail to bind to these sites, a weak binding activity of da is observed on the T5E1 site only, and the highest binding activity on all three sites is exhibited by hetero-oligomeric complexes of da and ac or da and sc. Thus, the relative potency of the $\mathrm{da}+\mathrm{ac}$ and $\mathrm{da}+\mathrm{sc}$ combinations in activating the expression of the $a c$ reporter is very likely to reflect the formation and function of $\mathrm{da} / \mathrm{ac}$ and $\mathrm{da} / \mathrm{sc}$ protein complexes in the transfected cells.

These experiments indicate that the ac and sc proteins, in combination with the da protein, are capable of high-level, direct transcriptional auto- and cross-activation of the $a c$ gene.

\section{Proper expression of an ac promoter-lacZ fusion gene in transgenic flies requires da/ac-sc DNA-binding sites}

The same 0.9-kb $a c$ promoter fragment used for the cotransfection studies (see Fig. 1A) directs expression of an Escherichia coli lac $Z$ reporter gene in the wing imaginal disc in a pattern that resembles the normal pattern of ac protein expression (Fig. 2A; Cubas et al. 1991; Martínez and Modolell 1991; Skeath and Carroll 1991). Moreover, we have verified that the spatial pattern of $l a c Z$ transcript accumulation from this $a c-l a c Z$ reporter in the wing disc is qualitatively similar to the distribution of the endogenous ac transcript (P.A. Powell, unpubl.). High-level expression of this reporter gene in the proneural cluster pattern is abolished in the ${s c^{10-1}}^{10}$ genetic background (Fig. 2B; Martínez and Modolell 1991). The $s c^{10.1}$ mutation severely reduces or inactivates the function of both the $a c$ and $s c$ genes (Garcia-Bellido 1979; Campuzano et al. 1985; Villares and Cabrera 1987), and adult male flies of the genotype $s c^{10-1} / Y$ completely lack sensory bristles on the thorax and head. Thus, the normal activity of the $a c$ promoter in the wing disc is dependent on the function of the endogenous $a c$ and $s c$ genes (Martínez and Modolell 1991).

Because the cotransfection experiments indicated that $\mathrm{da} / \mathrm{ac}-$ and $\mathrm{da} / \mathrm{sc}$-dependent activation of the $a c$ promoter in cultured cells requires the integrity of the three E-box binding sites within the $0.9-\mathrm{kb}$ fragment (Fig. $1 \mathrm{~B}, \mathrm{C}$ ), we investigated whether these sites are also required for the normal activity of the ac promoter in vivo. As shown in Figure 2, C and D, the high-level proneural cluster expression pattern of the wild-type promoterlac $Z$ fusion gene in the wing imaginal disc is abolished by mutation of the three da/ac-sc binding sites [this is the same mutant promoter used for the cotransfection experiments (Fig. 1B,C); the E box (CANNTG) sequence at all three sites was mutated to AANNTT]. The diffuse residual expression observed in the wing pouch and notum regions of the disc with the mutant promoter (Fig. $2 \mathrm{D} \mid$ is very similar to the residual expression exhibited by the wild-type promoter in an ac-sc mutant background $(\mathrm{Fig}$. $2 \mathrm{~B})$ and can also be seen underlying the proneural cluster expression pattern of the wild-type promoter in a wild-type background (Fig. 2A,C). It is possible that some or all of this expression is reflective of the initial, $a c / s c$-independent activation of the $a c$ promoter in the wing disc that is revealed by the reporter gene owing to the stability of the $\beta$-galactosidase protein.

These experiments demonstrate that mutation of the endogenous $a c$ and $s c$ genes (Fig. 2B), and mutation of the specific E-box binding sites for $\mathrm{da} / \mathrm{ac}$ and da/sc protein complexes in the $a c$ promoter (Fig. 2D), have very similar effects on $a c$ promoter activity in the wing imaginal disc. Both specifically eliminate the characteristic high-level proneural cluster pattern of $a c$ expression. Taken together with the in vitro DNA binding (Van Doren et al. 1991) and transcriptional activation (Fig. 1B,C) data, these results lead us to conclude that direct transcriptional autoregulation by the ac protein, and cross-regulation by sc, play an essential role in achieving the normal level of $a c$ expression in the wing imaginal disc.

\section{Ectopic sc expression results in ectopic ac promoter activity}

If the ac and sc proteins are direct transcriptional regulators of the $a c$ promoter, then ectopic expression and function of these proteins in imaginal discs should result in ectopic activation of the promoter. We tested this prediction by examining the spatial pattern of expression of the $a c-l a c Z$ promoter-reporter fusion gene in transgenic flies that also carried a $s c$ cDNA under the control of a heat shock promoter. When third-instar larvae of this type are subjected to heat shock regimens that give large numbers of ectopic macrochaete bristles on the notum of adult flies (Rodriguez et al. 1990; A. Singson, unpubl.), additional territories of $l a c Z$ expression are observed in the notum and wing primordia of the wing imaginal disc (Fig. 2E). Moreover, these new zones of ac promoter activity are located in the regions in which the precursors to the ectopic bristles are expected to appear (Bryant 1978; Huang et al. 1991). 

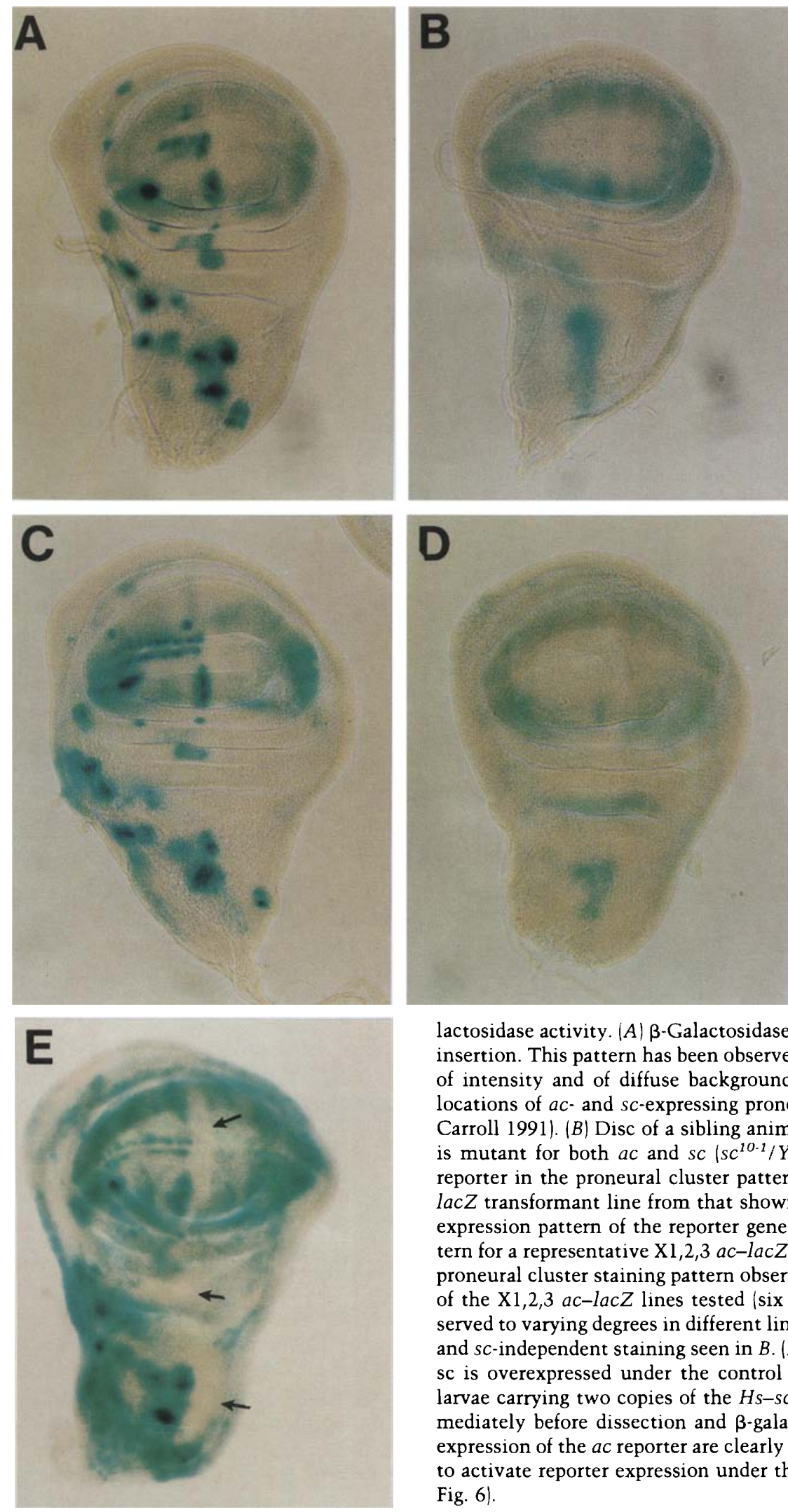

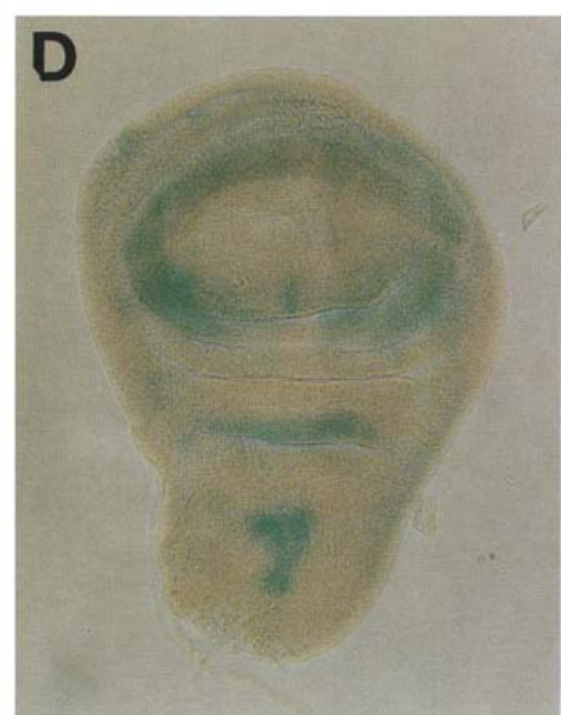
insertion. This pattern has been observed in all eight lines tested, with varying levels of intensity and of diffuse background staining. Strong staining is present at the locations of $a c$ - and $s c$-expressing proneural clusters (Cubas et al. 1991; Skeath and Carroll 1991). (B) Disc of a sibling animal from the same experiment as in $A$, which is mutant for both $a c$ and $s c\left(s c^{10-1} / Y\right)$. The high-level expression of the $a c-l a c Z$ reporter in the proneural cluster pattern is abolished. $(C)$ Disc from a different $a c-$ $l a c Z$ transformant line from that shown in $A$. This disc is somewhat older; the full expression pattern of the reporter gene is evident. $(D) \beta$-Galactosidase staining pattern for a representative $\mathrm{Xl}, 2,3$ ac-lacZ (mutant promoter) insertion line. The strong proneural cluster staining pattern observed in all $a c-l a c Z$ lines was observed in none of the $\mathrm{X} 1,2,3$ ac-lacZ lines tested (six lines). The diffuse residual staining was observed to varying degrees in different lines and is strikingly similar to the residual $a c$ and $s c$-independent staining seen in $B .(E) a c-l a c Z$ expression in a wing disc in which sc is overexpressed under the control of a heat shock promoter. Late third-instar larvae carrying two copies of the $H s-s c$ construct were subjected to heat shock immediately before dissection and $\beta$-galactosidase staining of discs. Areas of ectopic expression of the $a c$ reporter are clearly evident by comparison to $C$. Regions that fail to activate reporter expression under these conditions are indicated by arrows (cf.to Fig. 6). 
Rescue of bristle development by the ac gene in transgenic flies

The results presented above demonstrate the functional importance of the three $\mathrm{da} / \mathrm{ac}$-sc binding sites in the $a c$ upstream region for the normal level of expression of the $a c$ gene in the imaginal disc. To investigate the requirement for these sequences in promoting bristle development in the fly, we first tested the ability of the wildtype $a c$ gene to rescue bristle development in transgenic flies carrying the $s c^{10-1}$ mutation. As shown in Table 1 and Figure 3A, two copies of a 2.2-kb ac genomic DNA fragment (including the complete $a c$ transcription unit and the same $0.9 \mathrm{~kb}$ of $5^{\prime}$-flanking sequence used in the experiments described above) restore an average of nearly $40 \%$ of the wild-type number of microchaete bristles to $s c^{10-1}$ mutant flies. These bristles are organized in a well-spaced array that very strongly resembles the $\mathrm{mi}$ crochaete pattern of wild-type flies. If the three da/ac-sc DNA-binding sites in the 5'-flanking region of $a c$ are mutated, this rescue activity is greatly compromised (Table 1 ; Fig. 3B). This result indicates that these binding sites are functionally important in vivo in promoting the development of thoracic bristles. Because the rescue assay is carried out in a genetic background lacking $s c^{+}$ function, we suggest that the difference in rescue activity between the wild-type and mutant constructs is a measure of positive transcriptional autoregulation by the ac transgene.

\section{emc inhibition of ac promoter activation}

In an earlier study, we showed that the inhibitory HLH protein encoded by the emc gene specifically antagonizes the in vitro binding of $\mathrm{da} / \mathrm{da}, \mathrm{da} / \mathrm{ac}$, and $\mathrm{da} / \mathrm{sc}$ protein

Table 1. da/ac-sc binding sites in the ac promoter contribute to bristle development

\begin{tabular}{lcllr}
\hline \multicolumn{2}{c}{ Binding sites intact } & & \multicolumn{2}{c}{ Binding sites mutated } \\
\cline { 5 - 6 } line $($ no.) & mean \pm S.E. & & line $($ no.) & mean \pm S.E. \\
\hline C3-2 $(5)$ & $46.4 \pm 3.8$ & & D2-1 (5) & $6.4 \pm 2.2$ \\
C6-2 $(3)$ & $51.3 \pm 10.4$ & & D4-1 (5) & $11.4 \pm 1.9$ \\
C4-1 $(5)$ & $75.0 \pm 5.3$ & & D9-1 (5) & $17.8 \pm 4.2$ \\
C1-1 $(6)$ & $85.5 \pm 6.2$ & & D6-2 (7) & $24.1 \pm 2.4$ \\
C7-4 $(5)$ & $136.2 \pm 5.7$ & & D7-1 (8) & $59.5 \pm 2.0$ \\
Mean & 79.2 & & & 23.8
\end{tabular}

Male flies mutant for both $a c$ and $s c$ (genotype $s c^{10.1} / Y$ ) were made homozygous for a single transgene insert containing a 2.2 -kb fragment of the $a c$ gene. The three E-box binding sites in the promoter of this construct were either intact or mutated (CANNTG vs. AANNTT). The ability of the two constructs to promote bristle development was assayed by counting the number of microchaetes on the notum of the indicated number of flies. A wild-type male fly has $\sim 210$ notum microchaetes (Hartenstein and Posakony 1989), whereas $s c^{10 \cdot 1} / Y$ flies have none (García-Bellido 1979). Five independent inserts for each construct were tested. The means of the two groups are significantly different by the Mann-Whitney U Test $(P=0.028)$. complexes to the E-box sites upstream of the ac gene (Van Doren et al. 1991). It was suggested from these results that emc might act in vivo as a negative regulator of auto- and cross-regulation of the $a c$ and $s c$ genes. We tested the effect of emc on the activation of the $a c$ promoter by da and ac, or da and sc, in the tissue culture cotransfection assay. Figure 4 shows that transfection of increasing amounts of emc-encoding DNA progressively diminishes the level of $\mathrm{da} / \mathrm{ac}$ - or $\mathrm{da} / \mathrm{sc}$-dependent expression of the $a c$ reporter gene. The higher amounts of emc DNA tested reduce activation of the $a c$ promoter to levels very close to those observed in the absence of activator DNA. Thus, in the cotransfection model of $a c$ autoand cross-regulation, emc behaves as a dose-dependent inhibitor capable of abolishing the transcriptional activating function of the $\mathrm{da} / \mathrm{ac}$ and $\mathrm{da} / \mathrm{sc}$ combinations.

\section{Ectopic activity of the ac promoter in emc mutant imaginal discs}

The $e m c$ gene is named for the recessive ectopic bristle phenotype conferred by partial loss-of-function alleles (Botas et al. 1982; Moscoso del Prado and Garcí-Bellido 1984; García-Alonso and García-Bellido 1988). Figure 5, $\mathrm{A}$ and $\mathrm{B}$, illustrates the mutant phenotype of a strong hypomorphic allele, $e m c^{20}$, isolated in our laboratory (Lindsley and Zimm 1992). Ectopic macrochaetes appear at many positions on each heminotum, particularly between and anterior to the dorsocentral bristles, medial to the presutural bristle, between the postalar and supraalar bristles, and lateral to the dorsocentrals. We used this mutant to examine the effect of loss of emc function on the activity of the $0.9-\mathrm{kb} a c$ promoter fragment. In wing imaginal discs from third-instar larvae homozygous for $e m c^{20}$, the $a c-l a c Z$ reporter gene is expressed at high levels in many ectopic positions (Fig. 5C, D). These show a striking correspondence to the positions at which the precursors to the ectopic bristles shown in Figure 5B would be expected to arise (Bryant 1978; Huang et al. 1991). Thus, reduction of $e m c$ function in the wing imaginal disc permits the high-level activity of the ac promoter in territories from which it is normally excluded. This is very likely to be the basis of the ectopic appearance of cells expressing ac protein in emc mutant wing discs (Skeath and Carroll 1991).

\section{Inhibition of ac promoter activity in areas of high emc expression in the wing disc}

To investigate the spatial relationship between the pattern of $a c$ promoter activity and the pattern of emc expression, we subjected wing imaginal discs from late third-instar larvae carrying the $a c-l a c Z$ reporter to both $\beta$-galactosidase activity staining and in situ hybridization using an emc probe. Figure $6 \mathrm{~A}$ shows that there is a remarkable degree of complementarity between the distribution of $e m c$ transcripts (dark purple) and the pattern of $l a c Z$ expression driven by the $a c$ promoter (blue). In both the notum and wing pouch regions of the disc, ac promoter activity is excluded from areas of highest emc 

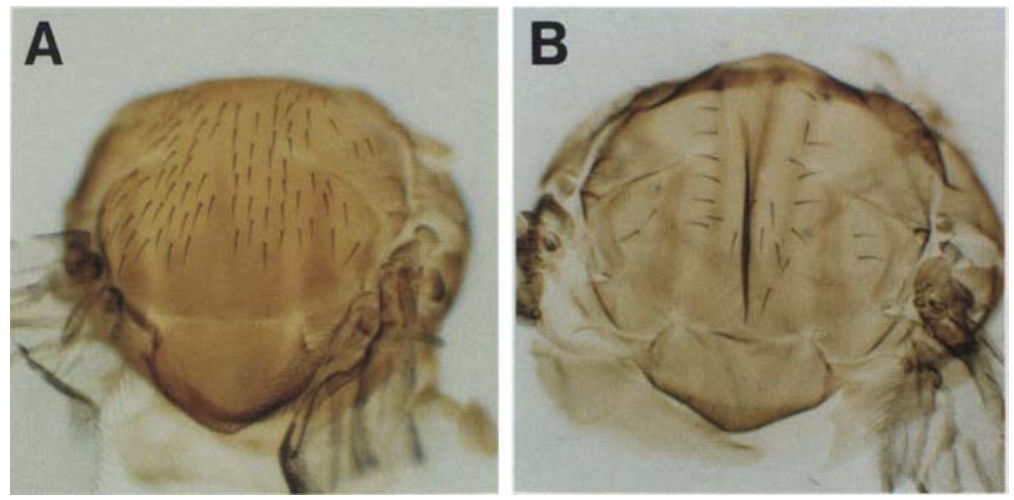

Figure 3. da/ac-sc binding sites in the $a c$ promoter contribute to bristle development. Representative results from the bristle rescue experiment are described in $\mathrm{Ta}$ ble 1 . Shown are dissected nota of transgenic flies carrying a $2.2-\mathrm{kb}$ fragment of the ac gene in a genetic background that is mutant for both $a c$ and $s c$ (genotype $s c^{10-1} / Y$ ). $S C^{10-1}$ flies are completely devoid of bristles on the notum (for details, see the legend to Table 1). $(A)$ ac gene with wild-type da/acsc binding sites (line C4-1). (B) ac gene with mutant da/ac-sc binding sites (line D6-2).

transcript accumulation and appears most intense in "holes" in the emc expression pattern. The borders of the lacZ-expressing territories often appear to abut directly on territories of high emc expression. To demonstrate more clearly the relationship between areas of low emc expression and the sites of appearance of SOPs, we carried out similar double-staining experiments with wing discs from late third-instar larvae carrying the enhancer trap transposon insertion A101, which is expressed in all SOPs and their progeny (Huang et al. 1991).

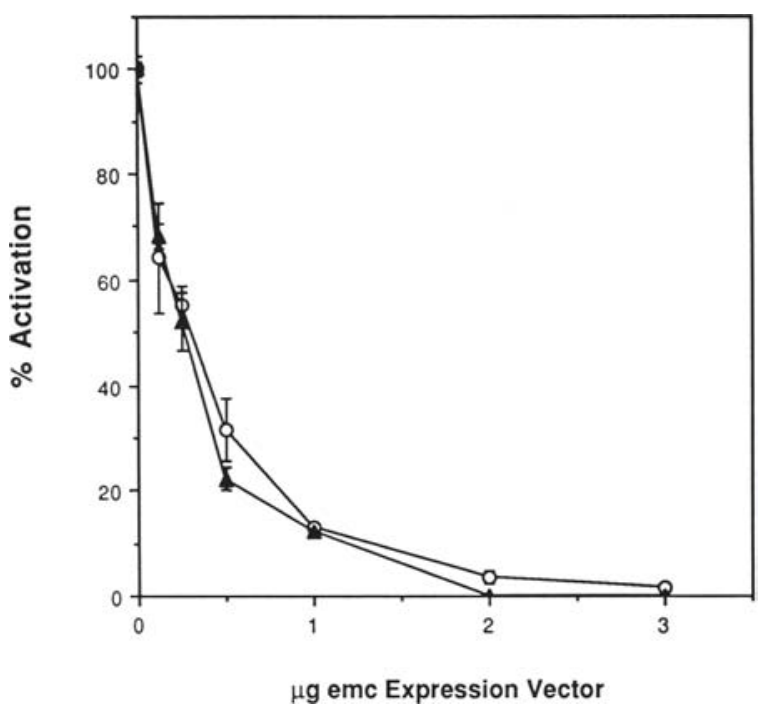

Figure 4. emc interferes with da/ac- and da/sc-dependent activation of the ac promoter. Shown are the results of representative tissue culture cotransfection experiments using the wildtype ac-CAT reporter construct (see legend to Fig. 1). Increasing amounts of emc expression vector $(0-3 \mu \mathrm{g})$ were included with a combination of either ac and da, or sc and da, expression vectors $(0.5 \mu \mathrm{g}$ each) in the cotransfection. The total amount of expression vector DNA was kept constant by including appropriate amounts of the parental expression vector with no insert. emc inhibits in a dose-dependent manner the normally strong activation of the $a c$ promoter by either ac + da $(O)$ or $s c+d a$ (A).
A typical result is shown in Figure $6 \mathrm{~B}$. In the notum region of the wing disc, it is clear that macrochaete SOPs arise in territories that are relatively devoid of emc transcript. In most instances, the SOP is surrounded by a "halo" of cells with low or no emc expression; these are presumably the remaining cells of the proneural cluster that express $a c$ (and $s c$ ) but do not become SOPs. Figure $6 \mathrm{~B}$ also demonstrates that the apparent exclusion of the in situ hybridization signal from areas of $\beta$-galactosidase positivity in Figure 6A is not an artifact of the staining procedure. A higher magnification view of the wing pouch region of a wing disc from the same Al01/emc double-staining experiment is shown in Figure 6C. The two rows of Al01-positive nuclei on the left side of the disc correspond to the precursors of the chemosensory bristles of the anterior wing margin (Hartenstein and Posakony 1989). These rows of precursors are clearly separated by a thin strip of high $e m c$ transcript accumulation. Figure 6C also shows a "stripe" of strong emc expression in the wing pouch region that lies approximately along the anterior/posterior compartment boundary, in the area between the L 3 and L 4 wing vein primordia (see also Fig. 6B).

We further investigated the relationship between emc expression and ac/sc activity in experiments illustrated in Figure 6, D and E. Wing discs taken from early to mid-third-instar larvae carrying the $a c-l a c Z$ reporter exhibit a pattern of emc transcript distribution that shows similarities to the pattern of later discs (Fig. 6D). ac-lacZ reporter expression is not yet detectable at the anterior wing margin in discs at this earlier stage, yet emc transcripts are already evident there, suggesting that emc expression in some areas precedes the establishment of high-level ac promoter activity. We also tested the possibility that the low level of emc transcript in ac-expressing proneural clusters is the result of a repressive action of ac and/or sc on emc expression in these areas. We examined the emc transcript distribution in wing discs from late third-instar male larvae carrying the $s c^{10-1} \mathrm{mu}$ tation, which inactivates both $a c$ and $s c$ (see above). As shown in Figure 6E, the emc expression pattern is evidently unchanged from that observed in wild-type discs of comparable age (see Fig. 6A,B). In particular, the ter- 

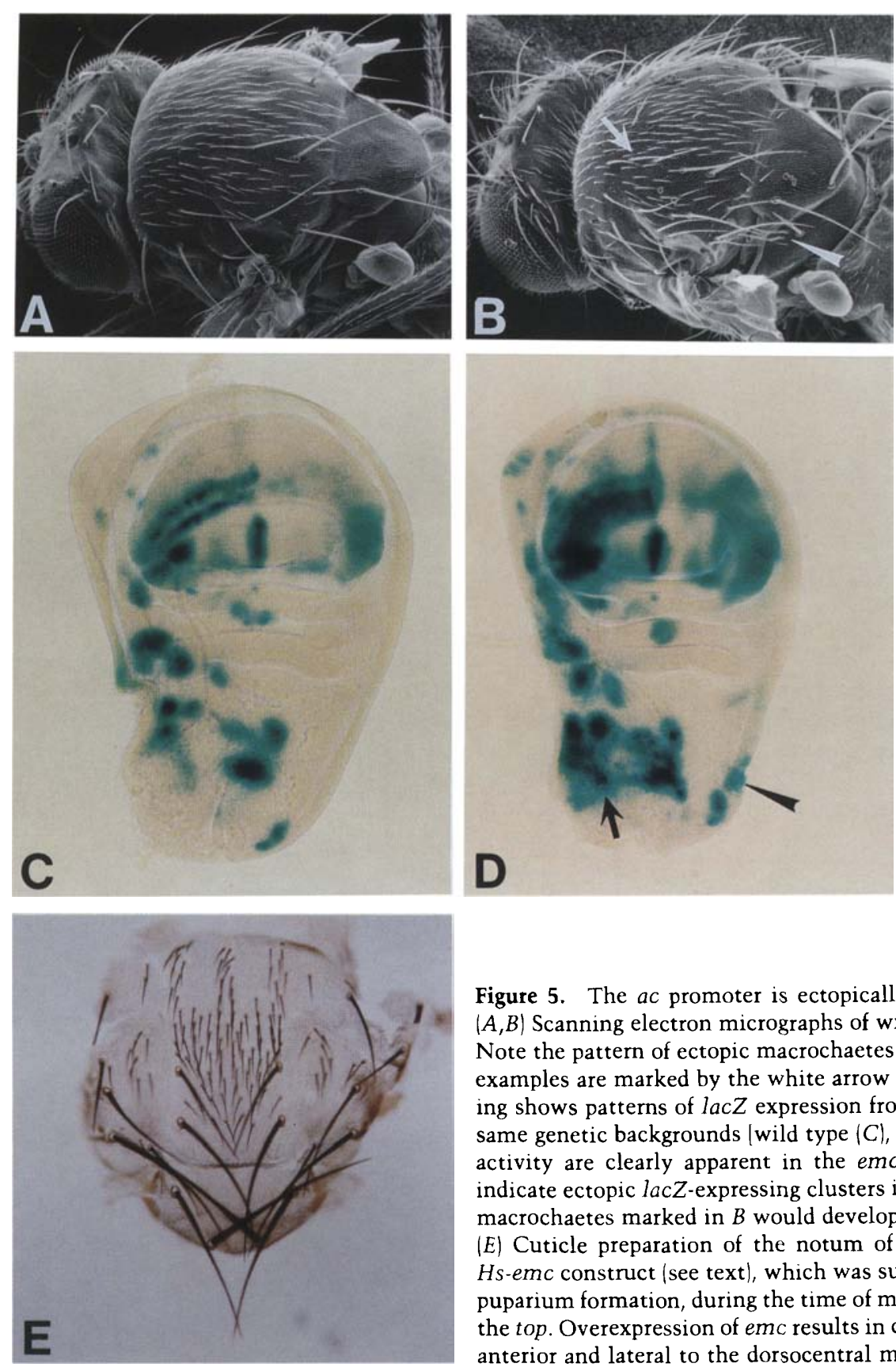

Figure 5. The ac promoter is ectopically activated in an emc mutant background. $(A, B)$ Scanning electron micrographs of wild-type $\left(w^{1118}\right)$ and $e m c^{20}$ flies, respectively. Note the pattern of ectopic macrochaetes on the head and notum of the $e m c^{20} \mathrm{fly}(B)$; examples are marked by the white arrow and arrowhead. $(C, D) \beta$-Galactosidase staining shows patterns of $l a c Z$ expression from the $a c-l a c Z$ reporter in wing discs of the same genetic backgrounds [wild type $\left.(C), e m c^{20}(D)\right]$. Positions of ectopic ac promoter activity are clearly apparent in the $e m c^{20} \operatorname{disc}(D)$. The arrow and the arrowhead indicate ectopic lac $Z$-expressing clusters in positions where the corresponding ectopic macrochaetes marked in $B$ would develop, according to the fate map of Bryant (1978). (E) Cuticle preparation of the notum of an adult fly containing four copies of the Hs-emc construct (see text), which was subjected to heat shock beginning at $6 \mathrm{hr}$ after puparium formation, during the time of microchaete SOP determination. Anterior is at the top. Overexpression of $e m c$ results in clear regions of microchaete loss, particularly anterior and lateral to the dorsocentral macrochaetes (cf. $E$ and $A$ ).

ritories of high and low expression in the notum region of the disc are readily apparent. This experiment demonstrates explicitly that the spatial modulations in $e m c$ transcript distribution in the late third-instar wing disc do not result from $a c$ - or $s c$-dependent regulation.

We showed above that overexpression of $s c$ driven by a heat shock promoter leads to high-level expression of the ac promoter in most, but not all, regions of the wing imaginal disc (Fig. 2E). A comparison of Figure 2E with Figure 6 reveals a close correspondence between areas that fail to activate the $a c-l a c Z$ reporter in response to $s c$ overexpression (arrows in Fig. 2E) and areas of highest $e m c$ transcript accumulation (e.g., Fig. 6B). This observation offers strong evidence that $a c$ promoter activity is antagonized in territories of high $e m c$ expression in the wing disc.

\section{Phenotypic consequences of overexpression of emc}

Our interpretation of the results presented here is that spatial variations in the level of emc expression play an important role in determining where in the wild-type imaginal disc auto- and cross-regulation of the ac gene can occur (see Discussion). If this view is correct, we 

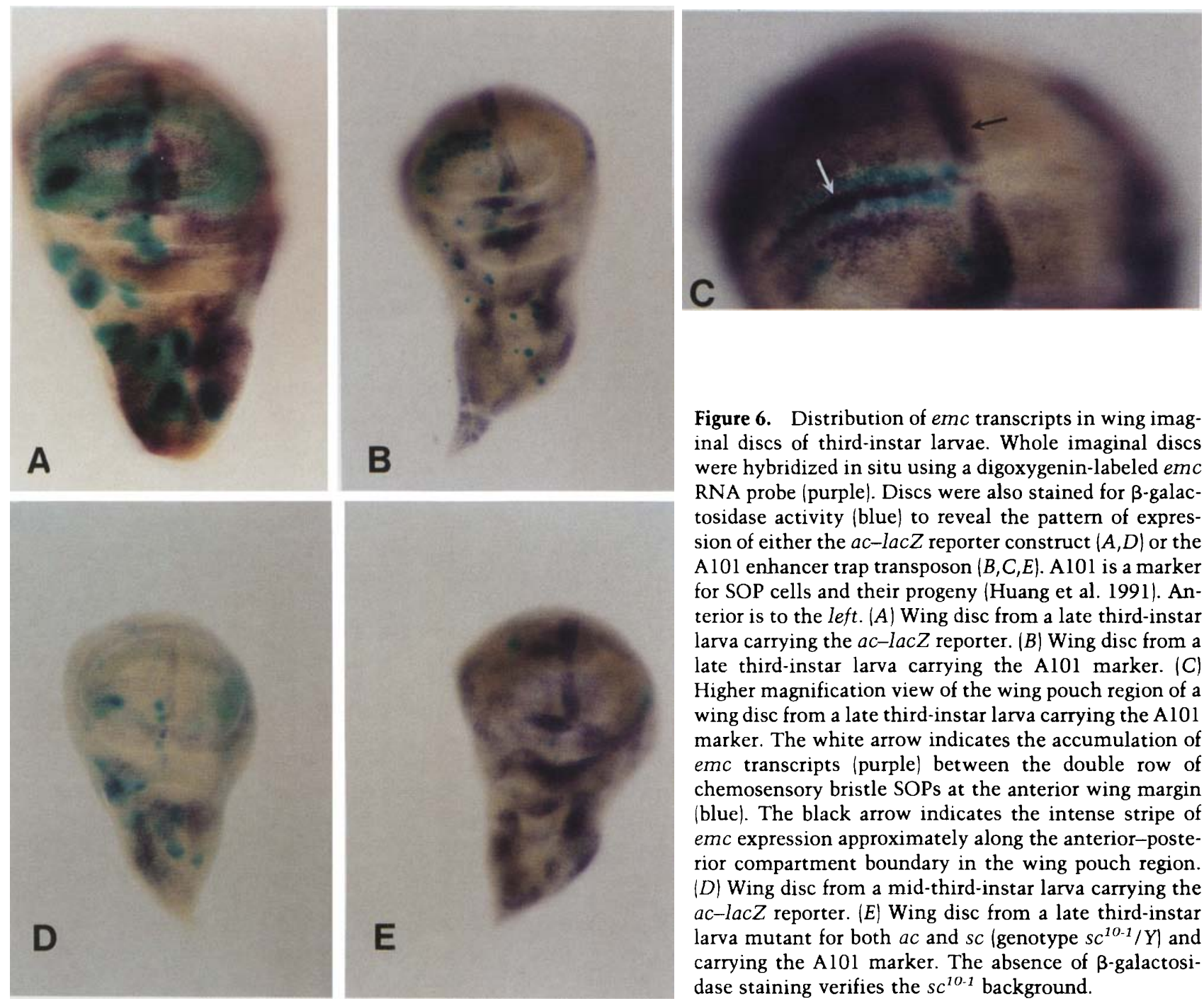

Figure 6. Distribution of $e m c$ transcripts in wing imaginal discs of third-instar larvae. Whole imaginal discs were hybridized in situ using a digoxygenin-labeled emc RNA probe (purple). Discs were also stained for $\beta$-galactosidase activity (blue) to reveal the pattern of expression of either the $a c-1 a c Z$ reporter construct $(A, D)$ or the A 101 enhancer trap transposon $\{B, C, E)$. Al01 is a marker for SOP cells and their progeny (Huang et al. 1991). Anterior is to the left. $(A)$ Wing disc from a late third-instar larva carrying the $a c-l a c Z$ reporter. $(B)$ Wing disc from a late third-instar larva carrying the Al0l marker. $(C)$ Higher magnification view of the wing pouch region of a wing disc from a late third-instar larva carrying the Al01 marker. The white arrow indicates the accumulation of emc transcripts (purple) between the double row of chemosensory bristle SOPs at the anterior wing margin (blue). The black arrow indicates the intense stripe of emc expression approximately along the anterior-posterior compartment boundary in the wing pouch region. $(D)$ Wing disc from a mid-third-instar larva carrying the $a c-l a c Z$ reporter. $\{E \mid$ Wing disc from a late third-instar larva mutant for both $a c$ and $s c$ (genotype $s c^{10-1} / Y$ ) and carrying the Al01 marker. The absence of $\beta$-galactosidase staining verifies the $s c^{10-1}$ background.

may expect that broad overexpression of emc (resulting in abnormally high levels of emc activity in normal proneural clusters) would cause the failure of normal bristles to develop. We tested this hypothesis by establishing lines of transgenic flies in which a wild-type emc cDNA is expressed under the control of the Drosophila Hsp70 promoter. When animals carrying four copies of this fusion gene are subjected to a heat shock regimen as early pupae, before the divisions of the microchaete precursor cells (Hartenstein and Posakony 1989), the resulting adult flies lack a large number of microchaete bristles on the head and notum (Fig. 5E). In contrast, the macrochaete bristles, which had already commenced differentiation at the time the heat shock was applied (Hartenstein and Posakony 1989), are unaffected. Earlier heat shocks, applied in the third larval instar before the division of the macrochaete SOPs, result in a reproducible pattern of macrochaete loss (data not shown). The anterior dorsocentrals, sternopleurals, presuturals, ocellars, and postverticals are especially sensitive to this treatment. Thus, broad overexpression of the wild-type emc protein is capable of interfering with normal sensory organ development, suggesting that the areas of low emc expression that we have observed in the wing disc (Fig. 6) are essential for the establishment of the normal adult bristle pattern.

\section{Discussion}

\section{Direct transcriptional activation of the ac promoter} by the ac and sc proteins

Several pieces of evidence lead us to the conclusion that the $a c$ promoter is subject to direct transcriptional activation in vivo by protein complexes that include the ac and sc proteins. First, as we have described previously, hetero-oligomeric complexes of da and ac, or da and sc, bind in a sequence-specific manner in vitro to three E-box sites upstream of the $a c$ transcription start /Van Doren et al. 1991). Second, in a cotransfection assay in 
Drosophila tissue culture cells, these same protein combinations are capable of activating by $>100$-fold the expression of a CAT reporter gene driven by a $0.9-\mathrm{kb}$ fragment of the $a c$ promoter; mutation of the three da/ac-sc binding sites abolishes this activation (Fig. 1). Third, the same 0.9 -kb promoter fragment drives high-level expression of a lacZ reporter gene in the wing imaginal discs of third-instar larvae in a proneural cluster pattern that is similar to that of the endogenous ac gene (Fig. 2; Martínez and Modolell 1991). High-level expression of the reporter in the cluster pattern is abolished in animals carrying loss-of-function mutations in the endogenous $a c$ and $s c$ genes (Fig. 2; Martínez and Modolell 1991). Finally, mutation of the three E-box binding sites greatly reduces or abolishes reporter gene expression in the proneural cluster pattern in vivo (Fig. 2).

These data do not strictly rule out the possibility that, in vivo, a protein or protein complex not involving ac or $\mathrm{sc}$ is responsible for the $\mathrm{E}$ box-dependent activation of $a c$ transcription in proneural clusters, and that ac and sc act indirectly. Such a hypothetical activator, however, must (1) be dependent for its expression or activity on $a c$ and $s c$ gene function, and (2) require the integrity of the core nucleotides of the E-box sites to which $\mathrm{da} / \mathrm{ac}$ and da/sc complexes bind in vitro. Given these constraints, we believe the simplest interpretation of the evidence is that the ac and sc proteins participate directly in transcriptional activation of the $a c$ gene in the proneural clusters of the wing imaginal disc.

The genetically defined requirement for both $d a$ and $a c / s c$ function in bristle development can be satisfactorily accounted for if these bHLH proteins function in vivo as da/ac or da/sc hetero-oligomeric complexes /Van Doren et al. 1991). However, although $d a$ is essential for the specification or execution of the SOP cell fate [at least in the larval PNS (Ghysen and O'Kane 1989)], it is not known whether high-level expression of $a c$ or $s c$ in imaginal disc proneural clusters or SOPs requires $d a^{+}$ function. It is possible that, in vivo, post-translational modifications, for example, allow ac and sc to function in auto- and cross-regulation independently of da. Similarly, da may have important functions in adult PNS development that do not require the presence of ac or sc. Nevertheless, the results described here (Fig. 1) and those of earlier studies (Cabrera and Alonso 1991; Van Doren et al. 1991) indicate that the intact ac and sc proteins are highly active in sequence-specific DNA binding and transcriptional activation only in the presence of the da protein.

\section{Role of auto- and cross-regulation of ac transcription in the development of proneural clusters}

Given our conclusion that $a c$ transcription in the wing disc is in part controlled by direct autoactivation, as well as cross-regulation by sc, it is useful to consider what function these activities serve in the process of sensory organ development. Their principal effect is to rapidly bring about a high level of $a c$ and $s c$ expression in the cells of the proneural clusters. This, in turn, may help to ensure that the competence to adopt the SOP cell fate is conferred in a robust manner on these cells, particularly the ultimate single SOP. Given the relatively transient nature of $a c / s c$ expression in both the clusters and in the SOP (Cubas et al. 1991; Skeath and Carroll 1991), highlevel expression of these genes may be necessary to achieve the required levels of target gene activity in a timely fashion.

An issue of obvious importance is whether ac autoactivation is important in vivo in promoting bristle development. We have addressed this question by an experiment that measures the ability of an $a c$ transgene to rescue microchaete development on the notum in a genetic background lacking endogenous $a c$ and $s c$ function. In these flies, the only source of functional ac protein is the transgene itself, cross-activation of the transgene by $s c$ is eliminated, and there is no direct $s c$ contribution to SOP determination. Thus, this appears to be a very stringent test of $a c$ autoregulation. Our finding that mutation of the three da/ac-sc DNA-binding sites in the ac promoter severely compromises the microchaete-promoting activity of the $a c$ gene (Fig. 3; Table 1 ) provides direct evidence that $a c$ autoactivation makes an important contribution to bristle patterning.

Mutual cross-activation of $a c$ and $s c$ appears to be responsible for the expression of both of these genes in the same final pattern following their initial activation in complementary patterns (Martínez and Modolell 1991, Skeath and Carroll 1991). It is not yet clear how important $a c$-sc cross-regulation is for most bristle development; however, because $s c$-dependent bristles do not generally require $a c$, and vice versa, only a single macrochaete, the posterior supra-alar, is genetically dependent on both $a c$ and $s c$ activity (Ghysen and DamblyChaudiere 1988). It is possible that in many proneural clusters, mutual cross-activation between $a c$ and $s c$ is a simple consequence of their autoregulatory activities, because the two proteins bind to the same sites in vitro (Cabrera and Alonso 1991; Van Doren et al. 1991).

\section{The emc protein interferes post-translationally with ac auto- and cross-regulation}

We have shown in this paper (Fig. 5) that an $a c-l a c Z$ reporter gene is expressed in ectopic proneural clusters in the wing imaginal discs of larvae carrying a strong partial loss-of-function mutation of emc. This indicates that the wild-type function of $e m c$ includes acting as a negative regulator of $a c$ promoter activity. Formally, the emc protein could accomplish this by direct transcriptional repression of $a c$, mediated by DNA binding. However, we believe that the evidence presented here and in our previous reports (Ellis et al. 1990; Van Doren et al. 1991) is most consistent with the interpretation that emc negatively regulates $a c$ transcription by interfering post-translationally with direct transcriptional autoactivation by ac and cross-activation by sc. First, the predicted emc protein shares the HLH dimerization domain of the bHLH proteins but lacks the conserved set of basic residues that constitute their DNA-binding domain, sug- 
gesting that it acts as a negative regulator by a mechanism involving protein-protein, rather than proteinDNA, interactions (Ellis et al. 1990; Garrell and Modolell 1990). Second, in vitro, emc antagonizes in a dosedependent manner the sequence-specific binding of $\mathrm{da} /$ ac and da/sc protein complexes to the E-box sites in the $a c$ promoter that we have shown are required for highlevel expression of the promoter in proneural clusters (Fig. 2; Van Doren et al. 1991). Recently, we have found that the HLH domain of emc is both necessary and sufficient for this in vitro activity (P.A. Powell and M. Van Doren, unpubl.). Third, in tissue culture cotransfection experiments, emc behaves as a dose-dependent inhibitor of $\mathrm{da} / \mathrm{ac}$ - and $\mathrm{da} / \mathrm{sc}$-dependent transcriptional activation of the ac promoter (Fig. 4).

We propose from these findings that post-translational inhibition of $a c$ and $s c$ auto- and cross-activation is one of the principal mechanisms by which emc negatively regulates ac/sc activity and, hence, sensory organ determination in the imaginal disc. (Transcriptional regulation of downstream genes by ac and sc will also be inhibited by this mechanism.) Our conclusion that transcription of the $a c$ gene is controlled in part by regulating its autoactivation function offers a precedent that may possibly be extended to other eukaryotic genes encoding transcription factors. It seems clear that any transcriptional regulator whose normal expression is dependent on an autoregulatory activity is potentially subject to spatial and temporal control at this level.

\section{emc and the spatial regulation of proneural gene} activity in the wing imaginal disc

Three observations reported here indicate that emc plays an important role in defining the spatial pattern of proneural clusters in the wing imaginal disc. First, emc transcripts are distributed nonuniformly in the disc (Fig. 6). Both the wing pouch and notum regions exhibit territories of high and low emc RNA accumulation. Second, the spatial pattern of ac/sc activity is, to a large degree, complementary to the pattern of emc expression. Thus, the ac lac $Z$ reporter is apparently not activated in territories of high emc expression; conversely, the highest levels of activation occur within zones of minimal emc transcript accumulation (Figs. $2 \mathrm{E}$ and $6 \mathrm{~A}, \mathrm{D}$ ). We have ruled out the possibility that this reciprocity is the result of a repressive action of ac and sc on emc by showing that the spatial pattern of emc transcript accumulation is established normally in the absence of $a c$ and $s c$ function (Fig. 6E). Finally, the ac promoter is strongly active in ectopic clusters of cells in the wing discs of an emc hypomorphic mutant (Fig. 5D), indicating that emc function is required in at least some parts of the disc to inhibit high-level ac transcription and thus SOP potential.

Our view of the role of emc in controlling the spatial pattern of $a c$ and $s c$ transcription, and thus the pattern of functional proneural clusters, is summarized in Figure 7. As described earlier (Van Doren et al. 1991), the normal development of the imaginal disc must include the activation of the $a c$ and $s c$ promoters not only in the areas in which proneural clusters appear, but also in territories where emc acts to suppress bristle development (Fig. 7A). We propose that the relatively high level of emc protein in these latter regions engages much or all of the available da, ac, or sc protein in hetero-oligomeric complexes that do not bind E-box sites with high affinity. These inactive emc-containing complexes are formed at the expense of complexes that are competent for sequence-specific, high-affinity DNA-binding and transcriptional activation (e.g., da/ac, and da/sc), thus preventing the establishment of stable auto- and cross-regulatory loops that would otherwise maintain $a c$ and $s c$ transcription at the levels characteristic of proneural clusters (Fig. 7B, right). In contrast, in territories of low or no emc expression (Fig. 7A,B, left), the ac and sc protein resulting from the initial activation of these genes is able to form functional dimeric complexes with da, establish stable auto- and cross-activation of both $a c$ and $s c$, and thus confer on the cells in these territories (the proneural clusters) the potential to adopt the SOP fate (by regulation of downstream target genes). In this model ectopic bristles develop in emc hypomorphic mutants (Fig. 7A, bottom) in part because the general reduction in $e m c$ activity in the disc causes the local emc activity in certain areas to fall below the threshold level necessary to inhibit $a c$ and $s c$ auto- and cross-activation, and this, in turn, results in the appearance of new proneural clusters and ultimately ectopic SOPs. Similarly, overexpression of sc allows it to overcome emc inhibition in certain areas and thus establish its auto- and cross-regulatory activities, resulting in ectopic proneural clusters (Fig. 2E) and ectopic bristles (Rodriguez et al. 1990; A. Singson, unpubl.). The bristle loss phenotype of the Hs-emc flies (Fig. 5E) can be explained in opposite terms. Broad overexpression of emc presumably results in elevating emc activity within areas that normally would have given rise to proneural clusters. This higher level of emc is capable of antagonizing $a c$ and $s c$ auto- and cross-activation, thus preventing SOP determination at these sites.

The spatial variation in emc transcript levels in the third-instar wing imaginal disc offers positional information of only moderate resolution (Fig. 6). Thus, our results indicate that although emc can help to define territories in which proneural clusters will arise and can limit the size of these clusters, it is insufficient to directly specify single SOPs. This is consistent with genetic observations that lateral inhibition, mediated by the neurogenic genes, is required to restrict the expression of the SOP fate to a single cell in each proneural cluster.

Although we believe that emc plays a critical early role in defining territories of bristle-forming potential in the wing imaginal disc, it is clear that other factors also function in this process. For example, the initial activation of the $a c$ and $s c$ genes is clearly patterned, because the two genes are first expressed in largely nonoverlapping spatial domains (Martínez and Modolell 1991; Skeath and Carroll 1991). In addition, we observe a number of territories in the disc that appear to lack both $a c$ promoter activity and emc expression (Fig. 6), further 
Figure 7. Schematic diagrams illustrating models of how spatial variations in emc expression control the pattern of $a c$ auto- and crossregulation in the imaginal disc $\{A\}$, and the establishment of positive autoactivation by the $a c$ gene and its inhibition by emc $(B)$ (for details, see text). (A) The scale at left indicates levels of expression (and/or activity) of $a c$ and emc. The broken lines represent the initial level of expression of $a c$. Hatched areas represent proneural clusters, where auto- and cross-activation increase ac transcription to higher levels. (Top) Wild-type fly; (bottom) emc hypomorphic mutant, with ectopic proneural cluster (central hatched region). (B) (Left) Establishment of positive autoregulation of the $a c$ gene in areas of low or no emc expression. (Right) Inhibition of $a c$ autoactivation in areas of high

B
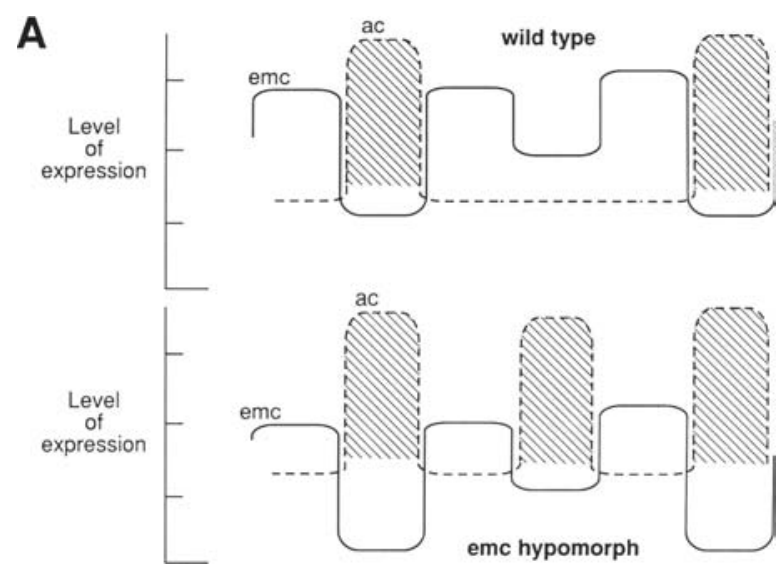
emc expression.
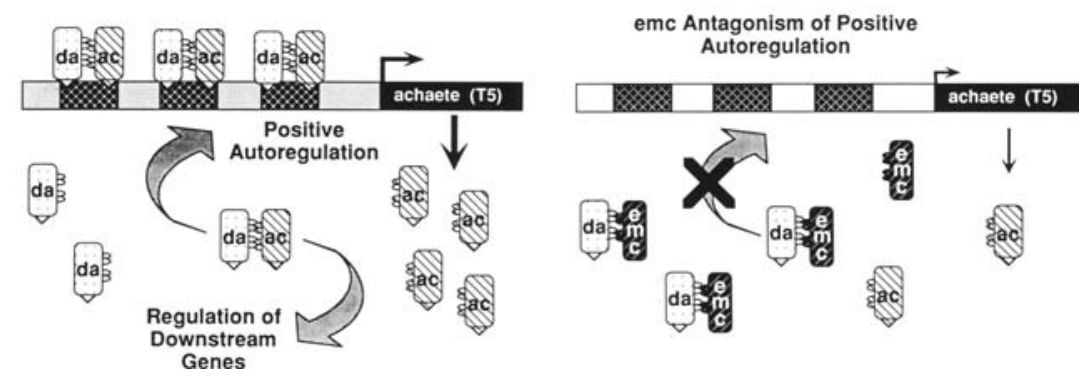

indicating that $a c$ expression is controlled by mechanisms not involving emc.

The nonuniform accumulation of emc transcripts in the wing disc immediately raises the question of what controls the spatial pattern of emc expression. For example, the strong stripe of $e m c$ RNA that we have observed approximately along the anterior/posterior compartment boundary in the wing pouch region may well be under the control of genes associated with this boundary, such as engrailed (Kornberg et al. 1985; Brower 1986), cubitus interruptus (Eaton and Kornberg 1990), and decapentaplegic (Masucci et al. 1990; Posakony et al. 1991). Thus, investigating the transcriptional regulation of $e m c$ expression in the wing disc may be a profitable approach to defining a connection between bristle patterning and the genes that provide positional information in the disc.

\section{Materials and methods \\ Drosophila stocks}

Flies were raised on standard yeast/cornmeal/molasses/agar medium. The $H s-e m c$ stock was homozygous for two different $\mathrm{P}[H s-e m c)$ insertions (see below). Hs-sc stocks were homozygous for one $\mathrm{P}[\mathrm{Hs}-\mathrm{sc}]$ insertion and were also homozygous for one $\mathrm{P}[a c-1 a c Z]$ insertion. All other stocks are described in Lindsley and Zimm (1992).

\section{Tissue culture}

Drosophila Schneider S2 cells were maintained in Schneider's Drosophila medium (GIBCO), supplemented with $12 \%$ fetal bo- vine serum, and were grown at room temperature. Cells were split $1: 5$ twice weekly.

\section{Mutagenesis of the ac upstream region}

Unless otherwise indicated, all molecular biology procedures are as described (Ausubel et al. 1987; Sambrook et al. 1989). A 2.2-kb EcoRI fragment containing the ac transcription unit /Villares and Cabrera 1987) was isolated from a Drosophila genomic DNA library. A $0.27-\mathrm{kb}$ DraI-BamHI fragment of this clone was ligated into SmaI/BamHI-digested pUC19. The resulting plasmid (pT5D-B) contains from -321 to -51 of the ac upstream region, which includes all three previously identified da/ac-sc binding sites: T5E1, T5E2, and T5E3 (Van Doren et al. 1991). Site-specific mutagenesis was performed using this plasmid, mutant oligonucleotides, convenient restriction sites, and the polymerase chain reaction (PCR) to generate a plasmid with mutations in these three sites (pT5D-BXI,2,3). The core E-box nucleotide sequence in each of the sites was changed from CANNTG to AANNTT, and this, as well as all PCR-synthesized DNA, was verified by double-stranded DNA sequencing. Owing to an apparent polymorphic difference between the published sequence of the $a c$ upstream region [used to design the oligonucleotides [Villares and Cabrera 1987)] and the sequence of our $a c$ clone, the wild-type and mutated $a c$ upstream regions also differ at position $-248(\mathrm{G}$ vs. A). Because this polymorphism was found in $a c$ genomic DNA clones from two wildtype stocks, we do not believe that this contributes significantly to the observed results.

\section{Plasmid construction}

The 2.2-kb EcoRI fragment of ac genomic DNA was subcloned into the EcoRI site of a derivative of pUCl9 in which the BamHI 
site had previously been eliminated. This plasmid (pT5-2.2) contains 875 bp of $a c$ upstream sequence, the entire $a c$ transcription unit, and $\sim 0.35 \mathrm{~kb}$ of downstream sequence (based on the $3^{\prime}$ end of our ac cDNA). A 0.9-kb EcoRI-Eco47III fragment from this clone was blunt-end-ligated into the HincII site of the same pUC19 derivative. This plasmid (pT5-0.9) contains from -876 to +14 of the $a c$ transcription unit. In addition, the wildtype NaeI-BamHI fragment in each of these plasmids was exchanged for the mutated NaeI-BamHI fragment from pT5D$\mathrm{BX} 1,2,3$ (see above). This created the plasmids pT5-2.2X1,2,3 and pT5-0.9X1,2,3, which are identical to pT5-2.2 and pT5-0.9, respectively, except that the T5E $1-T 5 E 3$ sites are specifically mutated. To create reporter constructs for cotransfection analysis, 0.9-kb PstI-XbaI fragments from both pT5-0.9 and pT5$0.9 \mathrm{Xl}, 2,3$ were cloned into PstI/XbaI-digested pC4CAT (Thummel et al. 1988), generating pT5-0.9CAT and pT5$0.9 \mathrm{X} 1,2,3 \mathrm{CAT}$, respectively. These constructs have $876 \mathrm{bp}$ of $a \mathrm{c}$ upstream sequence (including the ac transcription start site), with the da/ac-sc binding sites either intact or mutated, fused to the CAT-coding sequences. To create expression constructs for cotransfection analysis, cDNAs including the entire coding regions of $a c, s c$, da (A. Singson, unpubl.), and emc (Ellis et al. 1990) were placed under the control of the Drosophila actin 5C promoter in the vector pAct5CPPA (Han et al. 1989). For $a c$, an Eco47III-MscI fragment was first blunt-end-ligated into the SmaI site of pKSI + to create pKST5. A BamHI-KpnI fragment of pKST5 was then ligated into BamHI/KpnI-digested pAct5CPPA, generating pAcT5. For $s c$, an exonuclease-trimmed cDNA fragment [beginning at position 584 and ending at position 1806 of the published genomic DNA sequence (Villares and Cabrera 1987) ] was cloned into the XbaI site of pKS1 + using $X b a I$ linkers to create pKST4. A SacI-BamHI fragment of pKST4 was then ligated into SacI/BglII-digested pAct5CPPA, generating pAcT4. For da, a SacI-BamHI fragment of pKSda (Van Doren et al. 1991) was ligated into SacI/BglII-digested pAct5CPPA, generating pAcda. For emc, a RsaI-Rsal fragment was first blunt-end-ligated into the $\mathrm{XbaI}$ site of pGEM4 to make pGEM4emc (H. Ellis, unpubl.). pGEM4emc was digested with SalI and then subjected to a 2-bp fill-in using dCTP, dTTP, and Klenow DNA polymerase. A fragment containing the emc coding region was then liberated with a second digestion using BamHI. pAct5CPPA was digested with BamHI and also subjected to a 2-bp fill-in using dATP and dGTP, thereby generating a terminus compatible with ligation to the modified SalI terminus described above. pAct5CPPA was then digested with BgIII, and the two DNAs were ligated. Plasmid constructs for P element-mediated transformation made use of the CaSpeR vector (Pirrotta et al. 1988). For the bristle rescue experiments, the 2.2-kb EcoRI fragments from pT5-2.2 and pT5-2.2X1,2,3 were cloned into the EcoRI site of CaSpeR in the same orientation (pCSPT52.2 and pCSPT52.2X1,2,3). The ac-lacZ reporter gene was constructed using the vector CaSpeRlacZ (J. S. Margolis and J. W. Posakony, in prep.). This vector contains the $E$. coli lac $Z$ coding region and the SV40 small t polyadenylation site cloned into the multiple cloning site of CaSpeR. The identical PstI$X b a I$ fragments from pT5-0.9 and pT5-0.9X1,2,3 used to generate the CAT constructs were cloned into PstI/XbaI-digested CaSpeRlacZ, generating pCLZT5-0.9 and pCLZT5-0.9X1,2,3. These plasmids contain the identical $876 \mathrm{bp}$ of $a c$ upstream sequence as in the CAT constructs, with the da/ac-sc binding sites either intact or mutated, controlling expression of the lacZ gene. The CaSpeR-Hsp70 transformation vector for heat shock experiments is as described (Bang and Posakony 1992). For $\mathrm{P}[H s-s c]$, the $X b a I-l i n k e r e d$ fragment of $s c$ cDNA described above was directly cloned into CaSpeR-Hsp70. To make the $\mathrm{P}[\mathrm{Hs}-\mathrm{emc}]$ construct, an $\mathrm{XbaI}$ fragment containing the emc- coding region was isolated from pGEM4emc (above) and cloned into CaSpeR-Hsp70.

\section{Cotransfection analysis}

Cotransfection of plasmid DNAs into Drosophila Schneider cells was carried out using calcium phosphate precipitation (Sambrook et al. 1989). Approximately $2 \times 10^{6}$ to $4 \times 10^{6}$ cells were plated in each $60-\mathrm{mm}$ culture dish I day before transfection. A total of $10 \mu \mathrm{g}$ of DNA was used for each duplicate transfection and included $2 \mu \mathrm{g}$ of a plasmid containing a copia long terminal repeat (LTR)-lacZ fusion gene (Han et al. 1989), $2 \mu \mathrm{g}$ of either the pT5-0.9CAT or pT5-0.9X1,2,3CAT reporter constructs, $4 \mu \mathrm{g}$ total of expression vector DNAs /with or without cDNA insert; see above), and $2 \mu \mathrm{g}$ of pGEM4 (the DNA for a set of duplicates was precipitated together and then divided between the samples|. The cells were then incubated for 2 days with the precipitate. Cells were harvested by resuspension and were washed twice in PBS before being resuspended in $100 \mu$ l of $0.25 \mathrm{M}$ Tris- $\mathrm{HCl}(\mathrm{pH} 8.0)$. Cells were lysed by four cycles of freeze/thaw in dry ice/ethanol cycle, and lysates were clarified by centrifuging $5 \mathrm{~min}$ in a microcentrifuge. $\beta$-Galactosidase and CAT assays were performed as described (Gorman 1985). For all assays, CAT activity was normalized to $\beta$-galactosidase activity to control for transfection efficiency.

\section{P element-mediated germ-line transformation}

Transgenic flies were generated by standard $\mathrm{P}$ element-mediated germ-line transformation techniques (Rubin and Spradling 1982) using $w^{1118}$ as the recipient strain.

\section{$\beta$-Galactosidase staining of imaginal discs}

Imaginal discs of third-instar larvae were dissected in PBS and fixed for $2 \mathrm{~min}$ on ice in $1 \%$ glutaraldehyde in PBS. They were then stained for $\beta$-galactosidase activity as described (Romani et al. 1989).

\section{Double labeling by $\beta$-galactosidase activity staining and in situ hybridization}

Double staining of wing discs to detect $\beta$-galactosidase activity and emc transcript distribution was performed sequentially. Discs were first stained histochemically for $\beta$-galactosidase activity as described above. Following several washes in PBS $+0.1 \%$ Tween 20, discs were fixed as described /Schweisguth and Posakony 1992\}, and subsequent proteinase $\mathrm{K}$ and postfixation steps were performed according to Jiang et al. (1991). Discs were then subjected to in situ hybridization (Tautz and Pfeifle 1989) with a digoxygenin-labeled RNA probe synthesized from a full-length emc cDNA clone /pNB5b; Ellis et al. 1990).

\section{Heat shock experiments}

Heat shock treatments of $H s-s c$ (late third-instar larvae) and $H s-e m c$ (staged pupae) animals were carried out as described (Rodriguez et al. 1990; Bang and Posakony 1992). Immediately following the final heat shock, animals were dissected immediately for $\beta$-galactosidase staining (larvae in the $\mathrm{Hs}-\mathrm{sc}$ experiments) or were allowed to continue development to adulthood (Hs-emc pupae and some $H s-s c$ larvae). 


\section{Acknowledgments}

We are grateful to Ruth Schwartz for recovering genomic DNA clones containing the $a c$ gene, Ron Parsons for constructing the $H s-e m c$ plasmid, Hilary Ellis for constructing the four-copy $H s-e m c$ stock, Anne Bang for her help with the Hs-emc experiment and for instruction in scanning electron microscopy (SEM) techniques, Charles Graham of the Scripps Institution of Oceanography Analytical Facility for assistance with the SEM, Steve Small for plasmid DNAs and helpful discussions, Jacqueline Dyck for Schneider cells, and Kathy Hanley for help with statistical analysis. We thank Mike McKeown, Mike Levine, Steve Small, François Schweisguth, and Geoff Cereghino for critical reading of the manuscript and Janice Smith for secretarial assistance. This work was supported by a National Institutes of Health (NIH) predoctoral training grant (M.V.D.), a postdoctoral fellowship from the Muscular Dystrophy Association (P.A.P.), supplementary support from the University of California Cancer Research Coordinating Committee (P.A.P.), a National Science Foundation predoctoral fellowship (A.S.), and an NIH research grant (J.W.P.).

The publication costs of this article were defrayed in part by payment of page charges. This article must therefore be hereby marked "advertisement" in accordance with 18 USC section 1734 solely to indicate this fact.

\section{Note added in proof}

Recently, Cubas and Modolell [EMBO I. 11: 3385-3393 (1992)] reported results consistent with those described here concerning the spatial pattern of emc transcript accumulation in the wing imaginal disc. We note that these investigators have used the term "proneural fields" to describe the groups of cells referred to herein as "proneural clusters."

\section{References}

Alonso, M.C. and C.V. Cabrera. 1988. The achaete-scute gene complex of Drosophila melanogaster comprises four homologous genes. EMBO I. 7: 2585-2591.

Ausubel, F.M., R. Brent, R.E. Kingston, D.D. Moore, J.G. Seidman, J.A. Smith, and K. Struhl. 1987. Current protocols in molecular biology. Wiley/Greene, New York.

Bang, A.G. and J.W. Posakony. 1992. The Drosophila gene Hairless encodes a novel basic protein that controls alternative cell fates in adult sensory organ development. Genes \& Dev. 6: $1752-1769$.

Botas, J., J. Moscoso del Prado, and A. García-Bellido. 1982. Gene-dose titration analysis in the search of trans-regulatory genes in Drosophila. EMBO J. 1: 307-310.

Brower, D.L. 1986. engrailed gene expression in Drosophila imaginal discs. EMBO f. 5: 2649-2656.

Bryant, P.J. 1978. Pattern formation in imaginal discs. In The genetics and biology of Drosophila, (ed. M. Ashburner and T.R.F. Wright), pp. 229-335. Academic Press, New York.

Cabrera, C.V. and M.C. Alonso. 1991. Transcriptional activation by heterodimers of the achaete-scute and daughterless gene products of Drosophila. EMBO J. 10: 2965-2973.

Campuzano, S., L. Carramolino, C.V. Cabrera, M. Ruiz-Gomez, R. Villares, A. Boronat, and J. Modolell. 1985. Molecular genetics of the achaete-scute gene complex of D. melanogaster. Cell 40: 327-338.

Caudy, M., E.H. Grell, C. Dambly-Chaudiere, A. Ghysen, L.Y. Jan, and Y.N. Jan. 1988a. The maternal sex determination gene daughterless has zygotic activity necessary for the for- mation of peripheral neurons in Drosophila. Genes \& Dev. 2: 843-852.

Caudy, M., H. Vässin, M. Brand, R. Tuma, L.Y. Jan, and Y.N. Jan. 1988b. daughterless, a Drosophila gene essential for both neurogenesis and sex determination, has sequence similarities to myc and the achaete-scute complex. Cell 55: 1061-1067.

Cline, T.W. 1989. The affairs of daughterless and the promiscuity of developmental regulators. Cell 59: 231-234.

Cronmiller, C., P. Schedl, and T.W. Cline. 1988. Molecular characterization of daughterless, a Drosophila sex determination gene with multiple roles in development. Genes \& Dev. 2: 1666-1676.

Cubas, P., J.-F. de Celis, S. Campuzano, and J. Modolell. 1991. Proneural clusters of achaete-scute expression and the generation of sensory organs in the Drosophila imaginal wing disc. Genes \& Dev. 5; 996-1008.

Dietrich, U. and J.A. Campos-Ortega. 1984. The expression of neurogenic loci in imaginal epidermal cells of Drosophila melanogaster. . Neurogenet. 1: 315-332.

Eaton, S. and T. Kornberg. 1990. Repression of $c i-D$ in posterior compartments of Drosophila by engrailed. Genes \& Dev. 4: 1068-1077.

Ellis, H.M., D.R. Spann, and J.W. Posakony. 1990. extramacrochaetae, a negative regulator of sensory organ development in Drosophila, defines a new class of helix-loop-helix proteins. Cell 61: 27-38.

García-Bellido, A. 1979. Genetic analysis of the achaete-scute system of Drosophila melanogaster. Genetics 91: 491-520.

García-Alonso, L.A. and A. García-Bellido. 1988. extramacrochaetae, a trans-acting gene of the achaete-scute complex of Drosophila involved in cell communication. Wilhelm Roux's Arch. Dev. Biol. 197: 328-338.

Garrell, J. and J. Modolell. 1990. The Drosophila extramacrochaetae locus, an antagonist of proneural genes that, like these genes, encodes a helix-loop-helix protein. Cell 61:3948 .

Ghysen, A. and C. Dambly-Chaudière. 1988. From DNA to form: The achaete-scute complex. Genes \& Dev. 2: 495501.

Ghysen, A. and C.J. O'Kane. 1989. Neural enhancer-like elements as specific cell markers in Drosophila. Development 105: 35-52.

Gorman, C. 1985. High efficiency gene transfer into mammalian cells. In DNA cloning: A practical approach, (ed. D.M. Glover), pp. 143-190. IRL Press, Oxford, England.

Han, K., M.S. Levine, and J.L. Manley. 1989. Synergistic activation and repression of transcription by Drosophila homeobox proteins. Cell 56: 573-583.

Hartenstein, V. and J.W. Posakony. 1989. Development of adult sensilla on the wing and notum of Drosophila melanogaster. Development 107: 389-405.

-1990. A dual function of the Notch gene in Drosophila sensillum development. Dev. Biol. 142: 13-30.

Huang, F., C. Dambly-Chaudière, and A. Ghysen. 1991. The emergence of sense organs in the wing disc of Drosophila. Development 111: 1087-1095.

Jiang, J., D. Kosman, Y.T. Ip, and M. Levine. 1991. The dorsal morphogen gradient regulates the mesoderm determinant twist in early Drosophila embryos. Genes \& Dev. 5: 18811891.

Komberg, T., I. Siden, P. O'Farrell, and M. Simon. 1985. The engrailed locus of Drosophila: In situ localization of transcripts reveals compartment-specific expression. Cell 40: $45-53$.

Lindsley, D.L. and G. Zimm. 1992. The genome of Drosophila 
melanogaster. Academic Press, San Diego, CA.

Martinez, C. and J. Modelell. 1991. Cross-regulatory interactions between the proneural achaete and scute genes of Drosophila. Science 251: 1485-1487.

Masucci, J.D., R.J. Miltenberger, and F.M. Hoffmann. 1990. Pattern-specific expression of the Drosophila decapentaplegic gene in imaginal discs is regulated by $3^{\prime}$ cis-regulatory elements. Genes \& Dev. 4: 2011-2023.

Moscoso del Prado, J. and A. García-Bellido. 1984. Genetic regulation of the Achaete-scute complex of Drosophila mela. nogaster. Wilhelm Roux's Arch. Dev. Biol. 193: 242-245.

Murre, C., P.S. McCaw, and D. Baltimore. 1989. A new DNA binding and dimerization motif in immunoglobulin enhancer binding, daughterless, MyoD, and myc proteins. Cell 56: $777-783$.

Pirrotta, V. 1988. Vectors for P-mediated transformation in Drosophila. In Vectors: A survey of molecular cloning vectors and their uses (ed. R.L. Rodriguez and D.T. Denhardt), pp. 437-456. Butterworth, Stoneham, MA.

Posakony, L.G., L.A. Raftery, and W.M. Gelbart. 1991. Wing formation in Drosophila melanogaster requires decapentaplegic function along the anterior-posterior compartment boundary. Mech. Dev. 33: 69-82.

Rodriguez, I., R. Hernandez, I. Modolell, and M. Ruiz-Gomez. 1990. Competence to develop sensory organs is temporally and spatially regulated in Drosophila epidermal primordia. EMBO J. 9: 3583-3592.

Romani, S., S. Campuzano, E.R. Macagno, and J. Modolell. 1989. Expression of achaete and scute genes in Drosophila imaginal discs and their function in sensory organ development. Genes \& Dev. 3: 997-1007.

Rubin, G.M. and A.C. Spradling. 1982. Genetic transformation of Drosophila with transposable element vectors. Science 218: 348-353.

Rushlow, C.A., A. Hogan, S.A. Pinchin, K.M. Howe, M. Lardelli, and D. Ish-Horowicz. 1989. The Drosophila hairy protein acts in both segmentation and bristle patterning and shows homology to N-myc. EMBO I. 8: 3095-3103.

Sambrook, J., E.F. Fritsch, and T. Maniatis. 1989. Molecular cloning: A laboratory manual. Cold Spring Harbor Laboratory Press, Cold Spring Harbor, New York.

Schweisguth, F. and J.W. Posakony. 1992. Suppressor of Hairless, the Drosophila homolog of the mouse recombination signal-binding protein gene, controls sensory organ cell fates. Cell 69: 1199-1212.

Simpson, P. 1990. Lateral inhibition and the development of the sensory bristles of the adult peripheral nervous system of Drosophila. Development 109: 509-519.

Skeath, J.B. and S.B. Carroll. 1991. Regulation of achaete-scute gene expression and sensory organ pattern formation in the Drosophila wing. Genes \& Dev. 5: 984-995.

Tautz, D. and C. Pfeifle. 1989. A non-radioactive in situ hybridization method for the localization of specific RNAs in Drosophila embryos reveals translational control of the segmentation gene hunchback. Chromosoma 98: 81-85.

Thummel, C.S., A.M. Boulet, and H.D. Lipshitz. 1988. Vectors for Drosophila P-element-mediated transformation and tissue culture transfection. Gene 74: 445-456.

Van Doren, M., H.M. Ellis, and J.W. Posakony. 1991. The Drosophila extramacrochaetae protein antagonizes sequence-specific DNA binding by daughterless/achaete-scute protein complexes. Development 113: 245-255.

Villares, R. and C.V. Cabrera. 1987. The achaete-scute gene complex of D. melanogaster: Conserved domains in a subset of genes required for neurogenesis and their homology to myc. Cell 50: 415-424. 


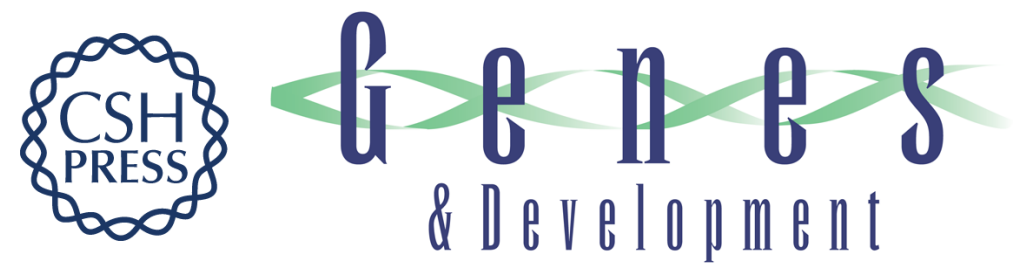

\section{Spatial regulation of proneural gene activity: auto- and cross-activation of achaete is antagonized by extramacrochaetae.}

M Van Doren, P A Powell, D Pasternak, et al.

Genes Dev. 1992, 6:

Access the most recent version at doi:10.1101/gad.6.12b.2592

References This article cites 41 articles, 18 of which can be accessed free at:

http://genesdev.cshlp.org/content/6/12b/2592.full.html\#ref-list-1

License

Email Alerting

Service right corner of the article or click here.

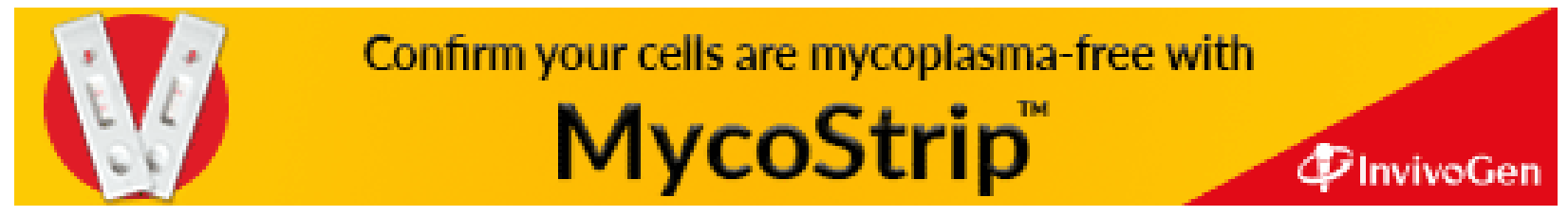

